\section{Comments on 'Midwives' experiences and views of giving postpartum contraceptive advice and long-acting reversible contraception: a qualitative study': authors' response}

We are grateful to Drs Walker and Davis for their letter ${ }^{1}$ which suggests that the views expressed by midwives in our study ${ }^{2}$ (regarding lack of knowledge and training on contraception) are likely to represent midwives' experiences throughout the UK. We also are pleased to learn that local initiatives are underway (such as those in Lanarkshire) to facilitate access to the contraceptive implant for selected groups of mothers. We feel that a national approach to midwifery training with greater emphasis on contraception is needed, in combination with close links between maternity services and local sexual health services, so that strategies such as those described by Drs Smith and McLellan ${ }^{3}$ can be successfully embedded as normal care for all postpartum mothers and can remain sustainable.

Sharon Cameron, ${ }^{*} \mathrm{MD}$, FRCOG

Consultant Gynaecologist, Chalmers Sexual and Reproductive Health Service, NHS Lothian, Edinburgh, UK and Consultant Gynaecologist, Royal Infirmary of Edinburgh, Edinburgh, UK;

sharon.cameron@ed.ac.uk

Kirsty McCance, BSC

Medical Student, College of Medicine and Veterinary Medicine, University of Edinburgh, Edinburgh, UK; kImccance@aol.com

*Corresponding author.

Competing interests None.

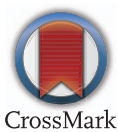

J Fam Plann Reprod Health Care 2014;40:313.

doi:10.1136/jprhc-2014-101064

\section{REFERENCES}

1 Walker S, Davis G. The views of final year student midwives on giving postpartum contraception and sexual health advice. J Fam Plann Reprod Health Care 2014;40:312.

2 McCance K, Cameron S. Midwives' experiences and views of giving postpartum contraceptive advice and long-acting reversible contraception: a qualitative study. J Fam Plann Reprod Health Care 2014;40:177-183.

3 Smith E, McLellan A. Comment on midwives' experiences and views of giving postpartum contraceptive advice and long-acting reversible contraception: a qualitative study'. J Fam Plann Reprod Health Care 2014;40:312-313. 